Jan H.M. Schellens · Wim Van de Vrie

Walter J. Loos · Herman J. Kolker · Jaap Verweij

Gerrit Stoter · Nico M.C. Durante

Alexander M.M. Eggermont

\title{
Pharmacokinetics of the multidrug-resistance-converting drug dexniguldipine and its pyridine metabolite $M-1$ in the plasma, tumor, and renal tissue of tumor-bearing Wag/Rij rats
}

Received: 7 January 1997 / Accepted: 1 June 1997

\begin{abstract}
The pharmacokinetics of oral dexniguldipine, a new multidrug-resistance-modifying agent under clinical evaluation, and its pyridine metabolite M-1 were determined in plasma, tumor, and renal tissue in Wag/ Rij rats bearing a multidrug-resistant CC531 colon adenocarcinoma tumor under the renal capsule. The pharmacokinetics were studied in four experiments. After a single administration of dexniguldipine $(30 \mathrm{mg} /$ $\mathrm{kg}$ ), tumors and kidneys were collected after 5 (experiment 1), 24 (experiment 2), and $48 \mathrm{~h}$ (experiment 3). In the fourth experiment, dexniguldipine was given once daily for 3 consecutive days at a dose of $30 \mathrm{mg} / \mathrm{kg}$. In all experiments, plasma samples were collected at regular intervals. The concentrations of dexniguldipine and M-1 could be determined in plasma in most of the rats at up to $32 \mathrm{~h}$ after drug administration. The area under the curve (AUC) of dexniguldipine and $\mathrm{M}-1$ varied by a factor of 2-6 in the four experiments. High tumortissue concentrations of dexniguldipine were observed. The concentrations were highest in the multiple-dose experiment $(2014 \pm 1005 \mathrm{ng} / \mathrm{g}$ tissue). High degrees of correlation $(>0.8)$ were established between the concentrations of dexniguldipine measured in plasma and tumor as well as renal tissue. Overall, tumor-tissue
\end{abstract}

J.H.M. Schellens · W.J. Loos · H.J. Kolker · J. Verweij · G. Stoter Laboratory of Experimental Chemotherapy and Pharmacology, Department of Medical Oncology, Rotterdam Cancer Institute,

Daniel den Hoed Kliniek/University Hospital Rotterdam, 3008 AE Rotterdam, The Netherlands

W. Van de Vrie · N.M.C. Durante · A.M.M. Eggermont Department of Surgery, Rotterdam Cancer Institute, P.O. Box 5201, 3008 AE Rotterdam, The Netherlands

W. Van de Vrie · A.M.M. Eggermont

Laboratory for Experimental Surgery, Erasmus University, P.O. Box 1738, 3000 DR Rotterdam, The Netherlands

J.H.M. Schellens $(\square)$

Netherlands Cancer Institute, Plesmanlaan 121,

1066 CX Amsterdam, The Netherlands

Tel.: 31-20-512 2569; Fax: 31-20-512 2572;

e-mail: JHM@NKI.NL concentrations of M-1 comprised one-third of the dexniguldipine concentrations measured.

Key words Dexniguldipine P Pharmacokinetics · Multidrug-resistance chemosensitizer

\section{Introduction}

Dexniguldipine is the (-) enantiomer of niguldipine, a dihydropyridine derivative. In in vitro studies, dexniguldipine has been found to bind to P-glycoprotein (P-gp) and to enhance the cytotoxicity of chemotherapeutic agents such as doxorubicin and etoposide in several cell lines resistant to these agents [3-5]. The synergistic effect may well be associated with reversal of multidrug resistance (MDR) related to the activity of $\mathrm{P}$-gp. Also, the pyridine metabolite M-1 has demonstrated pharmacologic activity [3-5, 8]. Dexniguldipine is extensively metabolized by the cytochrome P450 system and, most likely, by CYP (CYP 3A).

In addition, other in vitro studies have revealed that dexniguldipine itself has potent and selective cytotoxic activity against several tumor cell lines. The mechanism of cytotoxic action has not been fully elucidated, but interaction with protein kinase $\mathrm{C}$ and other parts of the intracellular signal-transduction pathway have been proposed [2, 12].

Many MDR-modifying agents have been applied in the clinic, such as verapamil, cyclosporin A, quinidine, and tamoxifen, among others $[9,11,13]$. The results obtained with verapamil have revealed serious cardiovascular side effects at levels of exposure that are presumably insufficient to achieve MDR reversal [10]. In addition, the lack of information about tumor-tissue concentrations of the MDR modifier has limited the optimal design of clinical studies with an MDR modifier and a P-gp-dependent anticancer agent $[6,17]$. The affinity of dexniguldipine for the calcium-channel receptor site is relatively low. This enables clinical administration of high doses of the drug. However, the resulting 
concentration range of the drug in tumor tissues has not been established. At present, dexniguldipine in combination with anticancer agents is undergoing phase $\mathrm{I} / \mathrm{II}$ clinical testing, for example, in small-cell lung cancer.

The aim of the present study was to explore the pharmacokinetics of dexniguldipine and its pyridine metabolite M-1 in the plasma, tumor, and renal tissue of Wag/Rij rats bearing an intrinsic MDR CC531 colon adenocarcinoma as a solid tumor under the renal capsule $[1,15]$.

\section{Materials and methods}

Experiments were approved by the Animals Ethics Board of the University of Rotterdam.

Assay of dexniguldipine and M-1 in plasma, tumor, and renal tissue

\section{Apparatus}

Dexniguldipine and M-1 were determined in plasma, tumor, and renal tissue using an automated reverse-phase isocratic high-performance liquid chromatography (HPLC) assay with UV detection at $230 \mathrm{~nm}$. A model 710B WISP autosampler and a model M510 pump were used (Waters Associates, Milford, Mess. USA). The detector was a UV2000 device (Spectra Physics, San Jose, Calif. USA). The data were processed with a Shimadzu CR3A integrator (Shimadzu Corporation, Kyoto, Japan). The column was a Shandon Hypersyl CPS column $(3 \mu \mathrm{m}, 150 \times 4.6 \mathrm{~mm}$; LC Service, Emmen, The Netherlands). The eluent consisted of $5 \mathrm{~m} M$ phosphate buffer $(\mathrm{pH} 7.5)$ with $60 \%$ acetonitrile. The flow rate was $1.5 \mathrm{ml} / \mathrm{min}$ and the column temperature was $40^{\circ} \mathrm{C}$. A volume of $100 \mu \mathrm{l}$ was injected into the HPLC system.

\section{Chemicals}

Dexniguldipine hydrochloride (B8509-035, batch 292-349), metabolite M-1 \{B8909-008, batch U1 29/071; chemical name 3-acetyl-2,6-dimethyl-4-nitrophenyl-5-[5-(4,4-diphenyl-1-piperidinyl)pentanoyl] pyridine fumarate $\}$, and the internal standard for the assay (B 9003-001, batch Zi 04/106) were obtained from Byk Gulden (Konstanz, Germany). All other chemicals were obtained from Baker (Deventer, The Netherlands) and were of analytical grade.

\section{Plasma-sample preparation}

A volume of $150 \mu \mathrm{l}$ plasma was collected, to which $50 \mu \mathrm{l}$ of a 2000$\mathrm{ng} / \mathrm{ml}$ solution of internal standard (B 9003-001, batch Zi 04/106) in methanol was added. A volume of $800 \mu \mathrm{l}$ deionized Milli-Q water was added, and the solution was mixed on a whirl mixer for $15 \mathrm{~s}$. For extraction a volume of $7 \mathrm{ml}$ dichloromethane (DCM)/ hexane/isobutylalcohol (40:60:0.5, by vol.) was added. The liquid was mixed for $30 \mathrm{~min}$ on a whirl mixer and subsequently centrifuged for $5 \mathrm{~min}$ at $4000 \mathrm{~g}$. The organic layer was collected and evaporated to dryness at $50{ }^{\circ} \mathrm{C}$ under vacuum. The residue was reconstituted in $150 \mu \mathrm{l}$ eluent. Calibration curves were constructed at up to $2000 \mathrm{ng} / \mathrm{ml}$. The recovery of dexniguldipine, M-1, and the internal standard was determined relative to the direct injection of the individual dissolved compounds.

\section{Tumor-tissue extraction}

Tumor tissue was homogenized with a Turrax homogenizer (Boom, Meppel) in $1 \mathrm{ml}$ Milli-Q water. The Turrax was flushed twice with $250 \mu \mathrm{l}$ Milli-Q water. A $50-\mu \mathrm{l}$ volume of a $2000-\mathrm{ng} / \mathrm{ml}$ internal standard solution in methanol was added. Subsequently, a 7-ml volume of DCM/hexane/isobutylalcohol (40:60:0.5 by vol.) was added and the mixture was vortexed for $30 \mathrm{~min}$. Thereafter the mixture was centrifuged for $5 \mathrm{~min}$ at $4000 \mathrm{~g}$. The organic layer was collected and evaporated to dryness at $50{ }^{\circ} \mathrm{C}$ under vacuum. The residue was reconstituted in $150 \mu \mathrm{l}$ eluent. The recovery of dexniguldipine, $\mathrm{M}-1$, and the internal standard was determined relative to the direct injection of the individual dissolved compounds.

\section{Construction of calibration curves at up to $500 \mathrm{ng}$ in tumor tissue}

Dexniguldipine hydrochloride (B8509-035, batch 292-349) and B8909-008 (M-1, batch U1 29/071) were added to clean test tubes and the samples were evaporated under vacuum. Approximately $100 \mathrm{mg}$ tumor tissue was added. Subsequently the procedure was carried out as outlined above.

\section{Tumor model and in vivo experiments}

Solid tumors of the CC531 colon adenocarcinoma tumor model were used according to a previously described method [7, 15]. Tumors of the intrinsic MDR cell line (CC531) were grown in donor $\mathrm{Wag} / \mathrm{Rij}$ rats. Tumor particles of 6-7 $\mathrm{mg}$ were prepared and implanted under the renal capsule of both kidneys of the rats (subrenal capsule model). In all pharmacokinetics experiments, two particles were implanted per kidney. For each experiment (i.e., 5-, 24-, 48-h, and repeated administration) a new tumor batch was grown in donor rats. In all rats the right jugular vein was cannulated in the pharmacokinetics experiments for blood sampling at regular intervals. The experiments were started on day 1 with tumor implantation. The rats were cannulated, after full recovery, on day 3 or 4 . During the experiments, diethyl ether anesthesia was applied. After termination of the experiments, rats were killed by cervical dislocation.

\section{Pharmacokinetics experiments}

An oral solution of $30 \mathrm{mg} / \mathrm{kg}$ dexniguldipine $(1.5 \mathrm{ml} / \mathrm{kg})$ was given through a thin metal oral cannula of 23 gauge on day 8 (single administration) or days 8-10 (repeated administration) after tumor implantation. Eight rats per treatment group were used. The solution consisted of an undiluted $2 \%$ dexniguldipine microemulsion (batch LSc 1974). The rats were given no food the night prior to the experiment. They had free access to drinking water. Blood samples were collected for up to 5 (5-h experiment), 24 (24-h experiment), or 48 (48-h experiment). The time points were $0,10,20,30,60$, and $120 \mathrm{~min}$ and $4,6,10,24,32$, and $48 \mathrm{~h}$. In the 5- and 24-h experiments the sampling times ended at 5 and $24 \mathrm{~h}$, respectively. Tumors and kidneys were collected immediately at the end of the sampling period. In the multiple-dose experiment, peak ( $2 \mathrm{~h}$ after drug intake) and trough (immediately prior to the next drug intake) blood samples were collected. Tumors and kidneys were collected at $5 \mathrm{~h}$ after administration of the final dose on day 10 . The area under the curve (AUC) was calculated using the lin-log trapezoidal method in all experiments. The Pearson correlation coefficient was calculated were appropriate.

\section{Results}

Assay of dexniguldipine and M-1 in plasma, tumor, and renal tissue

Results of the analysis of dexniguldipine and M-1 plasma

Calibration curves were linear up to the studied concentration of $2000 \mathrm{ng} / \mathrm{ml}$. Correlation coefficients were 


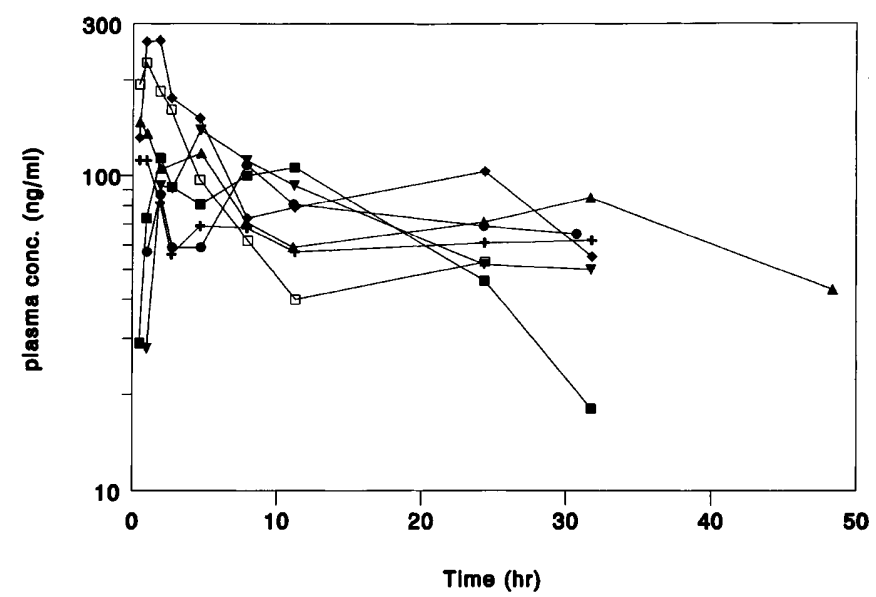

Fig. 1 Plasma concentration-time curves generated for dexniguldipine for up to $48 \mathrm{~h}$ in $7 \mathrm{Wag} / \mathrm{Rij}$ rats after a single oral administration of $30 \mathrm{mg} / \mathrm{kg}$ dexniguldipine. Data recorded for rat 8 were not evaluable

better than 0.999 . The lower limit of quantitation (LLQ) of dexniguldipine and M-1 was $25 \mathrm{ng} / \mathrm{ml}$. The betweenrun coefficient of variation $(\% \mathrm{CV})$ at the LLQ was $15.1 \%$ for dexniguldipine and $24.7 \%$ for $\mathrm{M}-1$. At almost all concentrations higher than the LLQ the $\% \mathrm{CV}$ was around $5 \%$ or lower.

\section{Results of the tumor-tissue extraction}

Calibration curves were linear up to the studied concentration of $500 \mathrm{ng}$. The correlation coefficients were $>0.999$. The LLQ of dexniguldipine and M-1 in tumor and renal tissue was $25 \mathrm{ng} / \mathrm{g}$.

\section{Pharmacokinetic experiments}

In the 5-h experiment, seven of the eight rats were evaluable for plasma kinetics of dexniguldipine and M-1 and all rats were evaluable for tumor- and renal-tissue uptake. The plasma AUCs determined for the 48-h experiment are given in Fig. 1. The AUC data are summarized in Table 1. The AUC of M-1 was always lower than that of the parent drug (Table 1). The concentra-

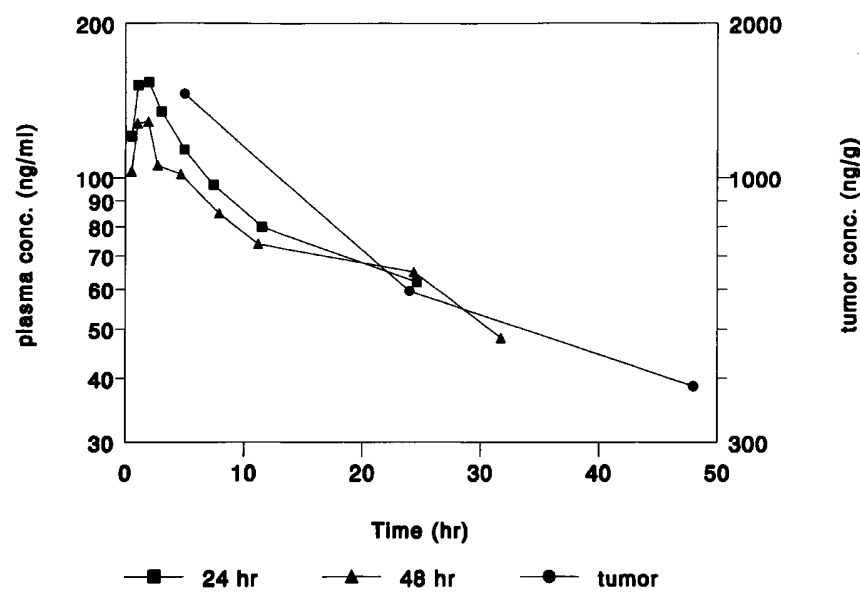

Fig. 2 Mean plasma concentration-time curves generated for the 24- and 48-h experiments, combined with the mean tumor concentrations obtained in the 5-, 24-, and 48-h experiments

tion-time curves generated for the 48-h experiment reveal that the plasma concentration at $48 \mathrm{~h}$ could be determined in only one of the rats. In almost all rats the concentration-time curves could be determined at up to $32 \mathrm{~h}$ after administration. The $\mathrm{AUC}_{0-48} \mathrm{~h}$ was calculated up to the latest measurable data point. The mean plasma concentration-time profiles obtained for the 24- and 48-h experiments were superimposable, which illustrates that the pharmacokinetics are reproducible (Fig. 2).

In the repeated-administration experiment, only limited plasma-kinetics data became available. Three cannulas became plugged and one rat was killed on day 1 of the 3-day experiment because of toxicity (reduced muscle tone, pilo erection, low blood pressure). The limited plasma-concentration data do not show major differences in the kinetics determined on days 1,2, and 3 .

The tumor concentrations of dexniguldipine and M-1 measured in the outlined experiments are given in Table 2 . The concentrations of M-1 were substantially lower than those of the parent drug.

The concentrations of dexniguldipine were higher in renal tissue than in tumor tissue (Table 2). Also, the M1 concentrations in renal tissue were on the order of $30 \%$ of the dexniguldipine concentrations, which resembles the relationship found in tumor tissue (data not shown).
Table 1 AUC data recorded for dexniguldipine and $\mathrm{M}-1$ in Wag/Rij rats after single or repeated oral administration of a dose of $30 \mathrm{mg} / \mathrm{kg}$ dexniguldipi$\mathrm{ne}^{\mathrm{a}}$ (Dex Dexniguldipine, $N E$ not evaluable)

\begin{tabular}{|c|c|c|c|c|c|c|}
\hline & \multicolumn{2}{|c|}{ 5-h experiment } & \multicolumn{2}{|c|}{ 24-h experiment } & \multicolumn{2}{|c|}{ 48-h experiment } \\
\hline & \multicolumn{2}{|c|}{$\begin{array}{l}\mathrm{AUC}_{0-5} \\
\left(\mu \mathrm{g} \mathrm{h} \mathrm{ml}^{-1}\right)\end{array}$} & \multicolumn{2}{|c|}{$\begin{array}{l}\mathrm{AUC}_{0-24} \\
\left(\mu \mathrm{g} \mathrm{h} \mathrm{m}^{-1}\right)\end{array}$} & \multicolumn{2}{|c|}{$\begin{array}{l}\mathrm{AUC}_{0-32} \\
\left(\mu \mathrm{g} \mathrm{h} \mathrm{ml}^{-1}\right)\end{array}$} \\
\hline & Dex & M-1 & Dex & M-1 & Dex & M-1 \\
\hline Mean & 0.67 & 0.16 & 2.17 & 0.64 & 2.49 & 0.54 \\
\hline SD & 0.80 & 0.15 & 1.03 & 0.34 & 0.64 & 0.43 \\
\hline Range & $0.22-2.47$ & $0.03-0.48$ & $1.15-4.31$ & $0.12-1.26$ & $1.76-3.49$ & $0.16-1.19$ \\
\hline
\end{tabular}

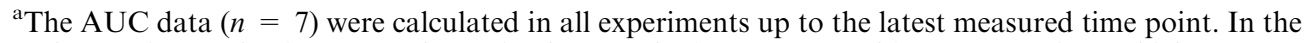
48-h experiment the AUC was determined up to the latest measurable concentration, which was detected at $31.7 \mathrm{~h}$ in all except one rat $(11.2 \mathrm{~h}$ in rat 6$)$ 
Table 2 Concentrations of dexniguldipine and metabolite M1 measured in tumor and normal renal tissue of rats at selected times after the administration of a single oral dose of $30 \mathrm{mg} / \mathrm{kg}$ dexniguldipine. Concentrations are expressed as mean values $\pm \mathrm{SD}$ $(n=7)$ in $\mathrm{ng} / \mathrm{g}$ tissue ${ }^{\mathrm{a}}$ (Dex Dexniguldipine)

\begin{tabular}{lccl}
\hline & $5 \mathrm{hr}$ & $24 \mathrm{hr}$ & $48 \mathrm{hr}$ \\
\hline Dex in tumor & $1463 \pm 1470$ & $595 \pm 404$ & $386 \pm 330$ \\
M1 in tumor & $398 \pm 293$ & $262 \pm 182$ & $146 \pm 107$ \\
Dex in renal tissue & $2707 \pm 1028$ & $2632 \pm 1811$ & $463 \pm 444$ \\
\hline
\end{tabular}

a Tumor tissue was obtained after the growth of implanted particles of CC531 adenocarcinoma in a renal subcapsular assay (see Materials and methods)

The order of magnitude of the renal concentrations recorded in the individual experiments was the same as that found in tumor tissue. The decline in the plasma concentration-time curves generated for the 24- and 48-h experiments paralleled the decline in the tumor-tissue concentrations of dexniguldipine, which illustrates the close relationship between the plasma kinetics and the tumor kinetics of dexniguldipine (Fig. 2). In this figure the tumor concentrations measured in the 5-, 24-; and 48-h experiments were combined for the construction of a concentration-time curve. Furthermore, high correlation coefficients were found between the tumor-tissue concentrations measured at the end of the experiment and the plasma AUC values obtained in the 5- $(R=0.98$, $n=7)$ and 24 -h experiments $(R=0.84, n=7$; Fig. 3$)$. The relationship between the tumor-tissue concentration and $\mathrm{AUC}_{0-48}$ was not calculated because the $\mathrm{AUC}_{0-48}$ value could not be determined in most of the rats, as is outlined above.

In addition, high correlation coefficients were found between tumor- and renal-tissue concentrations in all experiments ( $R$ values of at least 0.92). The tumor weights recorded in the four experiments varied and

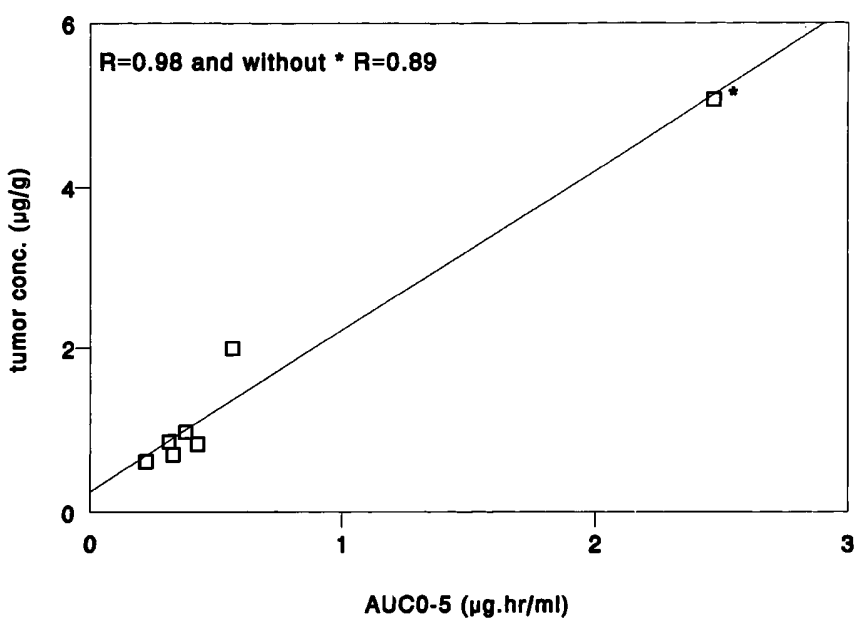

Fig. 3 Correlation between the tumor-tissue concentrations of dexniguldipine and the $\mathrm{AUC}_{0-5}$ determined in the 5-h experiment. The correlation coefficient was also calculated without the extreme observation $(*)$ were $63 \pm 19(5 \mathrm{~h}), 57 \pm 15(24 \mathrm{~h}), 131 \pm 42(48 \mathrm{~h})$, and $81 \pm 29 \mathrm{mg}$ (repeated administration).

\section{Discussion}

The present data describe the plasma, tumor, and renaltissue kinetics of dexniguldipine and its metabolite M-1 after single or repeated oral administration of $30 \mathrm{mg} / \mathrm{kg}$ dexniguldipine to tumor-bearing $\mathrm{Wag} / \mathrm{Rij}$ rats. The concentrations of dexniguldipine and metabolite $\mathrm{M}-1$ were determined in tumor tissue at 5,24 , and $48 \mathrm{~h}$ to evaluate the uptake kinetics in tumor tissue. In addition, the tumor concentrations were determined after 3 days of drug administration.

The plasma concentration-time curves generated for the 5-h experiment showed only a moderate decline. The kinetics in plasma were highly variable. In the 24-h experiment the AUC ranged from 1.15 to $4.31 \mu \mathrm{g} \mathrm{h} \mathrm{ml} l^{-1}$. In addition, the time to maximal plasma concentration $\left(T_{\max }\right)$ was highly variable (Fig. 1). Also, a study in humans has revealed that the pharmacokinetics are highly variable [14]. The elimination phase in the 48-h experiment was not long enough to enable calculation of the total AUC.

In the experiment involving repeated administration, limited plasma data became available due to plugging of three of the cannulas during the experiment. The plasma-concentration data recorded for the four evaluable rats revealed that the concentrations did not further increase after 2 days of dosing, indicating that nearsteady state had been reached. The administration once daily of $30 \mathrm{mg} / \mathrm{kg}$ dexniguldipine for 3 subsequent days was feasible except in one rat. No significant cumulative toxicity in the remaining animals was observed. A previous pilot experiment revealed that this dose was the highest feasible dose upon repeated administration in this model (data not shown).

The tumor concentrations of dexniguldipine and M-1 also showed wide variation (Table 2). It is unlikely that this variation would be due to differences in the distribution kinetics of dexniguldipine, considering the high degrees of correlation found between AUC values and tumor concentrations of dexniguldipine. The concentrations of the parent drug and M-1 were highest after repeated administration of the former. The high degrees of correlation found between plasma and tumor-tissue concentrations enable the prediction of tumor concentrations using plasma samples in this in vivo model. The high variability of the plasma concentrations may be attributable to variation between rats in the bioavailability of dexniguldipine.

High degrees of correlation were found between tumor- and renal-tissue concentrations of dexniguldipine. The renal-tissue concentrations were always a factor of 1.5-4 higher than the tumor-tissue concentrations, depending on the sampling time (Table 2). Dexniguldipine is a dihydropyridine derivative. This class of drugs is known to be extensively distributed in tissue. Differences 
in lipophilicity between tissues, e.g., renal and tumor tissue, may therefore contribute to the observation of differences in tissue concentration after exposure to dexniguldipine, in particular at steady state. The ratio of dexniguldipine to M1 was constant in all experiments.

The tumor weights showed variation between the experiments. The mean tumor weight measured in the 48-h experiment was clearly higher than that measured in the other experiments, which may have been due to tumor-batch differences. As a consequence, tumor growth-inhibition experiments should be carried out using the same tumor batch.

The in vitro results reported for the MDR-modifying effect of dexniguldipine revealed that dexniguldipine was highly active at a concentration as low as $50 \mathrm{ng} / \mathrm{ml}$ [16]. In that experiment the same CC531 cell line was used. It is hazardous to extrapolate the results of in vitro studies to in vivo tumor models. However, considering the very high tumor-tissue concentrations of dexniguldipine measured in vivo, it may be anticipated that these concentrations are high enough to reverse MDR in vivo. Results of the pharmacodynamics study of dexniguldipine and epidoxorubicin in this model reveal a moderately but significantly synergistic antitumor effect [16].

In the present study, high concentrations were achieved in intrinsically MDR solid-tumor tissue implanted under the renal capsule of rats after single and multiple oral dosing of the MDR-modifying drug dexniguldipine. In addition, the high degrees of correlation found between plasma and tumor-tissue concentrations enable the prediction of tumor concentrations in this model by simple measurement of plasma concentrations.

\section{References}

1. Gheuens E, Van der Heyden S, Elst H, Eggermont A, Van Oosterom A, De Bruijn E (1993) Multidrug resistance in rat colon carcinoma cell lines CC531, CC531 $1^{\mathrm{mdr}+}$ and CC531 $1^{\mathrm{rev}}$. Jpn J Cancer Res 84: 1201-1208

2. Gietzen K, Abdallah F, Bai G (1990) Inhibition of tumour cell growth by a novel dihydropyridine derivative. Eur J Cancer 26: 922-923

3. Hofmann J, Uerberall F, Egle A, Grunicke H (1991) B-859-35, a new drug with antitumor activity reverses multidrug resistance. Int J Cancer 47: 870-874
4. Hofmann J, Gekeler V, Ise W, Noller A, Mitterdorfer J, Hofer S, Utz I, Gotwald M, Boer R, Glossmann H, Grunicke HH (1995) Mechanism of action of dexniguldipine- $\mathrm{HCl}$ (B8509035), a new potent modulator of multidrug resistance. Biochem Pharmacol 49: 603-609

5. Höllt V, Kouba M, Dietel M, Vogt G (1992) Stereoisomers of calcium antagonists which differ markedly in their potencies as calcium blockers are equally effective in modulating drug transport by P-glycoprotein. Biochem Pharmacol 43: 26012608

6. Lum BL, Fisher GA, Brophy NA, Yahanda AM, Adler KM, Kaubisch S, Halsey J, Sikic BI (1993) Clinical trials of modulation of multidrug resistance. Cancer 72: 3502-3514

7. Marquet RL, Westbroek DL, Jeekel J (1984) Interferon treatment of a transplantable rat colon adenocarcinoma: importance of tumor site. Int J Cancer 33: 689-692

8. Noller A, Wilisch A, Häussermann K, Gekeler V (1992) MDR modulating and antineoplastic effects of B859-35 and its metabolite. Ann Oncol 3 [Suppl 1]: 71

9. Pastan I, Gottesman M (1987) Multiple-drug resistance in human cancer. N Engl J Med 316: 1388-1393

10. Pennock GD, Dalton WS, Roeske WR, Appleton CP, Mosley K, Plezia P, Miller TP, Salmon SE (1991) Systemic toxic effects associated with high-dose verapamil infusion and chemotherapy administration. J Natl Cancer Inst 83: 105-110

11. Raderer M, Scheithauer W (1993) Clinical trials of agents that reverse multidrug resistance. Cancer 72: 3553-3563

12. Schuller HM, Correa E, Orloff M, Reznik GK (1990) Successful chemotherapy of experimental neuroendocrine lung tumors in hamsters with an antagonist of $\mathrm{Ca}^{2+} /$ calmodulin. Cancer Res 50: 1645-1649

13. Sikic BI (1993) Modulation of multidrug resistance: at the threshold. J Clin Oncol 11: 1629-1635

14. Ukena D, Boewer C, Oldenkott B, Rathgeb F, Wurst W, Zech K, Sybrecht GW (1995) Tolerance, safety and kinetics of the new antineoplastic compound dexniguldipine- $\mathrm{HCl}$ after oral administration: a phase I dose-escalation trial. Cancer Chemother Pharmacol 36: 160-164

15. Van de Vrie W, Gheuens EEO, Durante NMC, De Bruijn EA, Marquet RL, Van Oosterom AT, Eggermont AMM (1993) In vitro and in vivo chemosensitizing effect of cyclosporin A on an intrinsic multidrug-resistant rat colon tumour. J Cancer Res Clin Oncol 119: 609-614

16. Van de Vrie W, Schellens JHM, Loos WJ, Kolker HJ, Verweij J, Stoter G, Durante NMC, Eggermont AMM (1996) Modulation of multidrug resistance with dexniguldipine hydrochloride (B8509-035) in the CC531 rat colon carcinoma model. J Cancer Res Clin Oncol 122: 403-408

17. Wishart GC, Bisset D, Paul J, Jodrell D, Harnett A, Habeshaw T, Kerr DJ, Macham MA, Soukop M, Leonard RCF, Knepil J, Kaye SB (1994) Quinidine as a resistance modulator of epirubicin in advanced breast cancer: mature results of a placebo-controlled randomized trial. J Clin Oncol 12: 17711777 